\title{
Comparative Fasting Lipid Profile in Relation to Time since Last Meal in Subjects with Type 2 Diabetes Mellitus: An Observational Study from a Tertiary Hospital in India
}

\author{
Arjun $\mathrm{B}^{1 *}$, Satinath $\mathrm{M}^{2}$ and Debasis $\mathrm{B}^{3}$ Subhankar $\mathrm{C}^{4}$ \\ ${ }^{1}$ Assistant Professor, Dept. of Endocrinology, N.R.S Medical College, India \\ ${ }^{2}$ Professor, Dept. of Endocrinology, IPGME\&R, SSKM Hospital, India \\ ${ }^{3}$ Professor and Head, Dept. of Biochemistry Malda Medical College and Hospital, India \\ ${ }^{4}$ Professor and Head, Dept. of Endocrinology, IPGME\&R, SSKM Hospital, India
}

\section{Research Article \\ Volume 1 Issue 1}

Received Date: March 07, 2017

Published Date: March 20, 2017

*Corresponding author: Arjun Baidya, Assistant Professor, Dept. of Endocrinology, N.R.S Medical College, AJC Bose Road, Kolkata, India. Tel:-+919433154618; E-mail: arjun.baidya@gmail.com

\section{Abstract}

Objective: Lipid profile is traditionally measured after twelve hours of fasting. Measurement of lipid profile after ten hours fasting state would be more convenient, particularly in diabetic subjects. This study was done to evaluate the extent of alteration of serum lipid profile parameters in relation to time since the last meal in subjects with type 2 diabetes mellitus.

Methods: Sixty subjects diagnosed as type 2 diabetes mellitus were included in this study. Ten and twelve hours fasting lipid profile were measured accordingly.

Results: Mean serum fasting total cholesterol, high density lipoprotein cholesterol (HDL-C) and low density lipoprotein cholesterol (LDL-C) at ten hours were $186.45 \pm 44.05 \mathrm{mg} / \mathrm{dL}, 45.28 \pm 12.25 \mathrm{mg} / \mathrm{dL}, 112.38 \pm 35.28 \mathrm{mg} / \mathrm{d}$ respectively and at 12 hours were $185.90 \pm 45.61 \mathrm{mg} / \mathrm{dL}, 45.03 \pm 12.44 \mathrm{mg} / \mathrm{dL}, 112.07 \pm 36.91 \mathrm{mg} / \mathrm{dL}$ respectively with no statistically significant difference ( $\mathrm{P}=0.61,0.47$ and 0.69 respectively). There was no statistically significant difference between median (interquartile range) triglycerides (TG) levels of $143(96-214) \mathrm{mg} / \mathrm{dL}$ and $150(103-226) \mathrm{mg} / \mathrm{dL}$ at $10^{\text {th }}$ and $12^{\text {th }}$ hours respectively ( $\mathrm{P}=0.57)$.

Conclusions: Ten hours fasting lipid profile was comparable to twelve hours fasting lipid profile without any significant difference. Therefore, this study concluded that fasting lipid profile after 10 hours since last meal may be recommended.

Keywords: Fasting; Lipid profile; Last meal; Type 2 diabetes mellitus

\section{Introduction}

Diabetic dyslipidemia is a well- known entity. The lipoprotein abnormalities commonly present in type 2 diabetes include hypertriglyceridemia and reduced plasma HDL cholesterol. In addition, low density lipoprotein (LDL) is converted to more atherogenic small dense LDL [1,2]. Current guidelines recommend that measurement of a fasting lipid profile for cardiovascular risk assessment is of utmost importance [3,4]. Lipids are traditionally being measured after an 8 to 12 hours fast to minimize the influence of postprandial lipemia [5]. 


\section{Open Access Journal of Endocrinology}

Ingestion of a typical fat-containing meal results in higher triglyceride levels and smaller changes in low-density lipoprotein (LDL) and high-density lipoprotein (HDL) cholesterol [6]. The third report of the National Cholesterol Education Program Adult Treatment Panel (Adult Treatment Panel III) recommends that initial screening should include a fasting lipid profile that includes total cholesterol, LDL cholesterol, HDL cholesterol, and triglycerides. The guidelines also allow for the measurement of total cholesterol and HDL cholesterol in the non-fasting state[3],as levels of these two lipids are altered minimally when measured in either fasting or non-fasting blood sample [7,8], Non-HDL cholesterol, a secondary target of therapy in Adult Treatment Panel III, may also be measured in the nonfasting state [3].

Lipid profile, done traditionally after 12 hours of fasting, is often inconvenient and may be potentially hazardous in patients of diabetes, especially in those who are prone to hypoglycaemia or in those who are on intensive management. To optimize fasting till 12 hours, often on the day of lipid profile testing morning doses of oral anti hyperglycaemic drugs or insulin need to be omitted or postponed, which may alter the glycaemic status of the patient. Therefore, most fasting lipid panels must be either planned before visits or checked at subsequent visits or it might require additional visits to outpatient phlebotomy centers. These rearrangements might lead many patients to miss their work for that day. All of these barriers might decrease physician as well as patient adherence to lipid screening guidelines in diabetes subjects. Since most Indians usually have their evening meal between $9 \mathrm{pm}$ and $10 \mathrm{pm}$ and would be ready to give a fasting blood sample by $8 \mathrm{am}$, a ten hours fasting state would be more convenient and time saving than 12 hours fasting. But before such practice is recommended, it needs to be investigated whether ten hours fasting lipid profile measurement provides the same information as that of 12 hours fasting. In the present study, we compared ten hours fasting lipid profile with 12 hours values in a cohort of type 2 diabetes subjects to observe the extent of alteration of measured parameters due to sampling at 10 hours vis-à-vis 12 hours since the last meal.

\section{Methodology}

This observational cross-sectional study was conducted between March 2010 to August 2011. Approval from the institutional ethics committee was obtained before conducting the study. Inclusion criteria were adult subjects with type 2 diabetes mellitus with $\mathrm{HbA}_{1 \mathrm{c}} \leq 7.0 \%$ and on oral antihyperglycaemic medications. Two hundred eighty adult type2 diabetes mellitus subjects from our diabetes clinic were initially screened for inclusion. Subjects on insulin and lipid modifying drugs, having chronic liver disease, chronic kidney disease, hypothyroidism or acute illness and history of regular alcohol intake were excluded. Sixty subjects satisfying the inclusion criteria were included in this study. Informed consent was obtained from all individual participants included in the study. Thorough history taking and clinical examination was done. The patients were subjected to anthropometric data measurement (height, weight, waist and hip circumference). The body mass index (BMI) was calculated using the formula (weight in kilograms)/(height in meter) ${ }^{2}$. Waist and hip circumferences were measured using standard techniques and the mean of two measurements was taken for calculating the waist-hip ratio (WHR).A predesigned format was used for registering patients' data.

Patients were instructed to take his or her usual diet at $10 \mathrm{pm}$ on the previous night and abstain from alcohol on the previous night. Blood samples were drawn at the outpatient clinic at $8 \mathrm{am}$ and $10 \mathrm{am}$ on the following day and patient had to remain fasting till the second sample was drawn. They were allowed to take only water and instructed to remain ambulatory in between. The samples thus collected were sent to the laboratory for lipid profile measurement. Serum was separated after centrifugation for measurement of lipid profile. Samples were analyzed on the same day in the biochemistry laboratory in our institution.

Fasting lipid profile were measured by fully automated chemistry analyzer (Trans Asia model no XL-600). Total cholesterol, triglyceride, were measured by enzymatic colorimetric method. LDL-C and HDL-C were estimated by direct specific enzymatic analysis following pre-treatment to remove unintended interfering lipoprotein particles. Descriptive statistics were presented in the form of mean, standard deviation, median; inter quartile range for data on continuous scale depending on the distribution of data. The normality of the study variables would be tested through Anderson Darling test, Shapiro-Wilk and QQ plot. The results on categorical measurements are presented in number (\%). Significance is assessed at $5 \%$. Comparison of ten hours fasting lipid profile values with those of 12 hours values were done by paired sample t-test and Wilcox on signed rank test. Analysis were performed using a software namely SPSS, version 16.0 for windows (Chicago, IL, USA).

\section{Results}

Mean age of the patients were $48.30 \pm 9.28$ yrs. Out of 60 patients, $25(41.7 \%)$ were male and $35(58.3 \%)$ were female. Mean BMI $\left(\mathrm{kg} / \mathrm{m}^{2}\right)$ of the patients were 


\section{Open Access Journal of Endocrinology}

23.97 \pm 3.36 . Sixty five percent patients had BMI $\geq 23$ and $35 \%$ patients had $\mathrm{BMI} \geq 25$. Mean waist circumference was $93.15 \pm 6.75 \mathrm{~cm}$ [(range (80 to 108)]. 63.3\% patients had waist circumference $\geq 90 \mathrm{~cm}$. Mean hip circumference was $90.83 \pm 5.14 \mathrm{~cm}$ and mean waist hip ratio was $1.02 \pm 0.04$. Mean duration of diabetes was $4.20 \pm 2.75$ years. Mean $\mathrm{HbA}_{1 \mathrm{c}}$ was $6.50 \pm 0.50 \%$ (Table 1).

\begin{tabular}{|c|c|}
\hline Male : Female(n=60) & $5: 07$ \\
\hline Age(yrs)( mean \pm SD) & $48.30 \pm 9.28$ \\
\hline $\begin{array}{c}\text { Duration of } \\
\text { diabetes(yrs)(mean } \pm \text { SD) }\end{array}$ & $4.23 \pm 2.75$ \\
\hline BMI $\left(\mathrm{kg} / \mathrm{m}^{2}\right)($ mean \pm SD) & $23.97 \pm 3.36$ \\
\hline $\begin{array}{c}\text { Waist } \\
\text { circumference(cm)(mean } \pm \text { SD) }\end{array}$ & $93.15 \pm 6.75$ \\
\hline Waist Hip ratio(mean \pm SD) & $1.02 \pm 0.04$ \\
\hline HbA $_{1 C}(\%)($ mean \pm SD) & $6.50 \pm 0.50$ \\
\hline
\end{tabular}

Mean fasting total cholesterol at 10 hours was $186.45 \pm 44.05 \mathrm{mg} / \mathrm{dL}$ and at 12 hours was $185.90 \pm 45.61$ $\mathrm{mg} / \mathrm{dL}$ and the difference was not statistically significant $(\mathrm{p}=0.61)$. Median fasting triglyceride at 10 hours was 143 (96-214) $\mathrm{mg} / \mathrm{dL}$ and at 12 hours was 150 (103-226) $\mathrm{mg} / \mathrm{dl}$ and the difference was not statistically significant $(\mathrm{p}=0.57)$. Mean fasting LDL-C at 10 hours was $112.38 \pm 35.28 \mathrm{mg} / \mathrm{dL}$ and at 12 hours was $112.07 \pm 36.91$ $\mathrm{mg} / \mathrm{dL}$ and the difference was not statistically significant $(\mathrm{p}=0.69)$. Mean fasting HDL-C at 10 hours was $45.28 \pm 12.25 \mathrm{mg} / \mathrm{dL}$ and at 12 hours was $45.03 \pm 12.44 \mathrm{mg} / \mathrm{dL}$ and the difference was not statistically significant $(\mathrm{p}=0.47)$ (Table 2 ).

Table1: Clinical characteristics of study population.

\begin{tabular}{|c|c|c|c|}
\hline Variables & $\begin{array}{c}\text { 10 hrs value (mean } \pm \text { SD)/Median } \\
\text { (IQ Range) } \mathbf{~ m g / d L ) ~}\end{array}$ & $\begin{array}{c}\text { 12 hrs value (mean } \pm \text { SD)/Median (IQ } \\
\text { Range) (mg/dL) }\end{array}$ & P value \\
\hline Total cholesterol & $186.45 \pm 44.05$ & $185.90 \pm 45.61$ & 0.61 \\
\hline Triglyceride & $143(96-214)$ & $150(103-226)$ & 0.57 \\
\hline LDL-cholesterol & $112.38 \pm 35.28$ & $112.07 \pm 36.91$ & 0.69 \\
\hline HDL-cholesterol & $45.28 \pm 12.25$ & $45.03 \pm 12.44$ & 0.47 \\
\hline
\end{tabular}

Table 2: Lipid profile of study population.

Note: LDL- Low density lipoprotein, HDL- High density lipoprotein.

\section{Discussion}

In this study we observed no significant difference in 10 hours and 12 hours value of triglyceride, total cholesterol, HDL cholesterol and LDL cholesterol. This observation supports the findings of previous study done by Mora et al. In a prospective study, except for triglyceride, they failed to detect significant changes in lipid concentrations since last meal. Triglyceride concentration was highest 4 to 5 hours postprandially and by 8 hours triglyceride level returned to fasting condition in most individuals [9]. Similar observation was also found by Langsted et al. They concluded that level of total cholesterol, LDL cholesterol, HDL cholesterol did not vary substantially, depending on what time of the day blood was drawn. However serum triglyceride concentration was elevated up to 6 hours after the last meal [10].
It should be considered whether median increases in fasting triglycerides of $7 \mathrm{mg} / \mathrm{dL}$, mean decreases in fasting total cholesterol, LDL and HDL cholesterol of 0.55 $\mathrm{mg} / \mathrm{dL}, 0.31 \mathrm{mg} / \mathrm{dL}$ and $0.25 \mathrm{mg} / \mathrm{dL}$ respectively in relation to time since last meal are of clinical importance. First, analytical and other physiological variation also may influence levels of lipids, lipoproteins [11], and this variation could be as large as or even larger than that attributed to time since last meal in the present study. Second, cardiovascular risk assessment is not based only on levels of lipids and lipoproteins, but these values are used with several other risk factors to estimate absolute 10-year risk of ischemic heart disease or cardiovascular death $[12,13]$. Therefore, these minor changes in lipid and lipoprotein levels after fasting will have only minimal influence on the estimated 10-year risk and thus on the decision to start lipid-lowering therapy. Third, neither American nor European guidelines on cardiovascular disease prevention use triglycerides for calculating 10 year risk [12,13], the lipid value mostly affected by fasting status; American guidelines suggest evaluating non-HDL cholesterol rather than triglycerides [12], and non-HDL 


\section{Open Access Journal of Endocrinology}

cholesterol was not significantly affected by time since last meal in the present study. Fourth, because European guidelines suggest that cardiovascular risk prediction is just as good regardless of whether HDL cholesterol is included, a minimal change in HDL cholesterol of $0.25 \mathrm{mg} / \mathrm{dL}$ in relation to time since last meal certainly would not have a major impact on cardiovascular risk prediction. Finally, statin trials have documented that clinically important reductions in total and LDL cholesterol should be $\geq 40 \mathrm{mg} / \mathrm{dL} \quad[12,13]$, also questioning whether a change in the detected levels of total and LDL cholesterol of $0.55 \mathrm{mg} / \mathrm{dL}$ and $0.33 \mathrm{mg} / \mathrm{dL}$ respectively resulting from fasting in relation to time since meal is clinically important.

The changes in cholesterol values over time have also been studied in relation to retesting of adult patients with normal and abnormal baseline cholesterol values. In these subjects, coefficients of variation for results of retests within a person over time ranged between $6 \%$ and $11 \%$ for the various cholesterol components $[14,15]$. For adult patients with elevated total cholesterol, this would result in individual variation with an SD of between 15 and 23 $\mathrm{mg} / \mathrm{dL}$. Although the testing procedure we used was different, and the variation in our study was across a sample instead of within a person, the change in mean values based on fasting status is likely less important clinically than longitudinal changes over time or even than test-retest variation. Interestingly, a recent metaanalysis found that fasting and non-fasting triglyceride levels were equally good at predicting increased risk of coronary heart disease [16].

However, there are some limitations of our study. Firstly, the concern about residual confounding in a nonrandomized observational study cannot be excluded. Secondly, small number of patients is another limitation because it might decrease power to detect statistically significant differences between 10 and 12 hours fasting values. A third limitation is that we had no record of exactly what each participant had eaten before blood sampling on the previous night.

On the other hand, our study represents the "real world" where usually no such information is available before blood sampling. Fourth, it could be argued that the time since the last meal was self-reported and subject to error; however, the time since the last meal was confirmed at the exact time of blood sampling. Finally, in the present study, we include only subjects with type2diabetes; therefore, our results may not necessarily be applicable to subjects with type 1 diabetes and subjects without diabetes.
Future prospective research could include studies on the predictive value of levels of lipids, lipoproteins, and apolipo proteins for cardiovascular disease risk according to the time since the last meal before blood sampling.

\section{Conclusion}

From our study it can be concluded that there is no significant difference between the 10 hours and 12 hours lipid profile. Therefore, it may be recommended to measure a fasting lipid profile after 10 hours since last meal. However, before that further large randomized study is needed.

\section{References}

1. Mokdad AH, Ford ES, Bowman BA, William H Dietz, Frank Vinicor, et al. (2003) Prevalence of obesity, diabetes, and obesity-related health risk factors 2001. JAMA 289(1): 76-79.

2. Mokdad AH, Bowman BA, Ford ES, Vinicor F, James S Marks, et al. (2001) The continuing epidemics of obesity and diabetes in the United States. JAMA 286(10): 1195-1200.

3. Third Report of the National Cholesterol Education Program (NCEP) Expert Panel on Detection, Evaluation, and Treatment of High Blood Cholesterol in Adults (Adult Treatment Panel III) final report (2002). Circulation 106(25): 3143-3421.

4. De Backer G, Ambrosioni E, Borch-Johnsen K. (2003) European guidelines on cardiovascular disease and prevention in clinical practice. Atherosclerosis 171: 145-155.

5. Bachorik PS, Ross JW (1995) National Cholesterol Education Program Working Group on Lipoprotein Measurement. National Cholesterol Education Program recommendations for measurement of lowdensity lipoprotein cholesterol: executive summary. Clin Chem 41(10): 1414-1420.

6. Rifai N, Dufour DR, Cooper GR (2000) Preanalytical variation in lipid, lipoprotein, and apolipoprotein testing. Handbook of Lipoprotein Testing. 2nd ed. Washington DC: AACC Press.

7. Craig SR, Amin RV, Russell DW, Paradise NF (2000) Blood cholesterol screening influence of fasting state on cholesterol results and management decisions. J Gen Intern Med 15(6): 395-399. 


\section{Open Access Journal of Endocrinology}

8. Wilder LB, Bachorik PS, Finney CA, Moy TF, Becker DM (1995) The effect of fasting status on the determination of low-density and high-density lipoprotein cholesterol. Am J Med 99(4): 374-377.

9. Mora S, Rifai N, Buring JE, Ridker PM (2008) Fasting compared with nonfasting lipids and apolipoproteins for predicting incident cardiovascular events. Circulation 118(10): 993-1001.

10. Langsted A, Freiberg JJ, Nordestgaard BG (2008) Fasting and nonfasting lipid levels: influence of normal food intake on lipids, lipoproteins, apolipoproteins, and cardiovascular risk prediction. Circulation 118(20): 2047-2056

11. Rifai N, Warnick GR (2006) Lipids, lipoproteins, apolipoproteins, and other cardiovascular risk factors. Textbook of Clinical Chemistry and Molecular Diagnostics. Philadelphia, Pa: Elsevier Saunders.

12. Executive summary of the Third Report of the National Cholesterol Education Program (NCEP) (2001) Expert Panel on Detection, Evaluation, and Treatment of High Blood Cholesterol in Adults (Adult Treatment Panel III). JAMA 285(19): 2486-2497.
13. De Backer G1, Ambrosioni E, Borch-Johnsen $\mathrm{K}$, Brotons C, Cifkova R, K et al. (2003) European guidelines on cardiovascular disease prevention in clinical practice: Third Joint Task Force of European and Other Societies on Cardiovascular Disease Prevention in Clinical Practice. Eur Heart J 24(17): 1601-1610.

14. Takahashi 01, Glasziou PP, Perera R, Shimbo T, Suwa $\mathrm{J}$, et al. (2010) Lipid re-screening: what is the best measure and interval? Heart 96(6): 448-452.

15. Glasziou PP, Irwig L, Heritier S, Simes RJ, Tonkin A (2008) LIPID Study Investigators. Monitoring cholesterol levels: measurement error or true change? Ann Int Med 148: 656-661.

16. Sarwar N, Danesh J, Eiriksdottir G, Sigurdsson G, Wareham N, et al. (2007) Triglycerides and the risk of coronary heart disease: 10,158 incident cases among 262,525 participants in 29 Western prospective studies. Circulation 115(4): 450-458. 